\title{
DTNBPI (Dysbindin) Gene Variants Modulate Prefrontal Brain Function in Healthy Individuals
}

\author{
Andreas J Fallgatter*,', Martin J Herrmann', Christa Hohoff', Ann-Christine Ehlis', Tomasz A Jarczok', \\ Christine M Freitag ${ }^{3}$ and Jürgen Deckert ${ }^{2}$ \\ 'Laboratory for Psychophysiology and Functional Imaging, Department of Psychiatry, University of Würzburg, Würzburg, Bavaria, Germany; \\ ${ }^{2}$ Department of Psychiatry, University of Münster, Münster, Germany; ${ }^{3}$ Department of Child and Adolescent Psychiatry, Saarland University \\ Hospital, Homburg (Saar), Germany
}

\begin{abstract}
DTNBPI (dysbindin) is one of the several putative schizophrenia genes supported by association, neuroanatomical, and cellular studies. These suggest an involvement of DTNBPI in the prefrontal cortex and cognitive functions mediated by interaction with neurotransmitter systems, in particular glutamate. The influence of DTNBPI gene variation on prefrontal brain function at the systemic neurophysiological level, though, has not been characterized. The NoGo-anteriorization (NGA) as an event-related potential (ERP) measure elicited during the continuous performance test (CPT) has been established as a valid neurophysiological parameter for prefrontal brain function in healthy individuals and patients with schizophrenias. In the present study, we therefore investigated the influence of eight dysbindin gene variants on the NGA as a marker of prefrontal brain function in 48 healthy individuals. Two DTNBPI polymorphisms previously linked to schizophrenia (PI765 and PI320) were found associated with changes in the NGA. Post hoc analysis showing an influence of genetic variation at these loci on the Go centroid and frontal amplitudes suggest that this might be due to modification of the execution of motor processes by the prefrontal cortex. This is the first report on a role of DTNBPI gene variation for prefrontal brain function at a systemic neurophysiological level in healthy humans. Future studies will have to address the relevance of this observation for patients with schizophrenias.
\end{abstract}

Neuropsychopharmacology (2006) 31, 2002-20 I0. doi: I0.1038/sj.npp. I 30 I003; published online I I January 2006

Keywords: DTNBPI (dysbindin); genetic variation; prefrontal brain; Go NoGo; NoGo-anteriorization; endophenotype

\section{INTRODUCTION}

$D T N B P 1$ (dysbindin) is a recently characterized protein that binds to alpha-beta-dystrobrevins and is part of the dystrophin protein complex in muscle and nonmuscle cells. Variations in the human DTNBP1 gene located on chromosome $6 \mathrm{p} 22.3$ have been reported to be associated with schizophrenia by several groups (eg Straub et al, 2002; Schwab et al, 2003; van den Oord et al, 2003; VanDenBogaert et al, 2003; Kirov et al, 2004; Williams et al, 2004; for a review see Funke et al, 2004) and a mutation has been reported to be the cause of Hermansky-Pudlak syndrome type 7 (Li et al, 2003).

In the brain, DTNBP1 may influence glutamatergic neurotransmission by multiple post- and presynaptic

\footnotetext{
*Correspondence: Dr AJ Fallgatter, Laboratory for Psychophysiology and Functional Imaging, Department of Psychiatry and Psychotherapy, University of Wuerzburg, Füchsleinstr. 15, Würzburg, Bavaria 97080, Germany. Tel: +49931201 77100, Fax: +49931 201 77550,

E-mail: Fallgatter_A@klinik.uni-wuerzburg.de

Received 3 May 2005; revised 20 September 2005; accepted 2 November 2005

Online publication: 4 November 2005 at http://www.acnp.org/citations/ Npp I 10405050286/default.pdf
}

mechanisms, partly independent of the dystrophin protein complex and including modulation of other, for example, GABAergic, nicotinic, and dopaminergic neurotransmitter systems (Harrison and Weinberger, 2005). In primary cortical neuronal culture, DTNBP1 appears to influence exocytotic glutamate release via upregulation of molecules in the presynaptic machinery and to promote neuronal viability through PI3-kinase-Akt signaling (Numakawa et al, 2004). In the hippocampus of schizophrenic patients, reductions of $D T N B P 1$ expression were observed in terminal fields of intrinsic, glutamatergic afferents of the subiculum, the hippocampus, and the inner molecular layer of the dentate gyrus, which correlated with increases in vesicular glutamate transporter-1 (VgluT-1) (Talbot et al, 2004). Reductions of DTNBP1 gene expression were also observed in the dorsolateral prefrontal cortex of schizophrenic patients and expression correlated with DTNBP1 genotype (Weickert et al, 2004). It was suggested that these changes in DTNBP1 gene expression in the hippocampus and prefrontal cortex contribute to the cognitive deficits observed in patients with schizophrenias.

During the last years, a new field of research in biological psychiatry has emerged, which was coined imaging genomics (eg Hariri and Weinberger, 2003). The basic idea 
is that certain genetic variants affecting neurotransmission systems may change brain activity in a way that is measurable by neuroimaging methods, in particular functional magnetic resonance tomography. However, also electrophysiological measures seem suitable for such a purpose, since twin and family studies have shown that characteristics of the spontaneous EEG in general, but also of P300 event-related potentials (ERPs) are highly heritable (van Beijsterveldt and van Baal, 2002). Moreover, P300 abnormalities known from schizophrenic patients are also found in their healthy siblings (Winterer et al, 2003).

Accordingly, the first report in that new field of imaging genomics (Fallgatter et al, 1999a) described a topographical change in an ERP measure during an inhibitory task associated with the presence of a short allele of the serotonin transporter promoter polymorphism (SERT; Lesch et al, 1996). Meanwhile, several other groups reported an influence of this genetic variant on brain activity in the amygdale of healthy subjects (eg Canli et al, 2005) as well as an interaction with stressful life events in depressed patients (Caspi et al, 2003). A similar research strategy resulted in a series of studies highlighting the influence of a genetic variant affecting the dopaminergic neurotransmission (COMT Val158Met polymorphism) on the function of the dorsolateral prefrontal cortex in healthy subjects (eg Winterer and Goldman, 2003) as well as psychiatric patients (eg Egan et al, 2001). Studies investigating the influence of other genetic variants besides SERT and COMT on brain function are rare in general and absent in the case of dysbindin.

Over the last years, our research group has developed an electrophysiological method for the quantitative measurement of prefrontal brain function, which is based on the comparison of ERPs elicited during the Go and the NoGo condition of the CPT. The more anterior located P300 topography in NoGo as compared to Go trials has been denoted as NoGo-anteriorization (NGA) and is characterized by a very high interindividual stability (Fallgatter $e t a l$, 1997). Moreover, the NGA is independent of age and gender (Fallgatter et al, 1999b) and has a very high short-term (Fallgatter et al, 2001) and long-term (Fallgatter et al, 2002a) test-retest reliability. Replicated three-dimensional electrophysiological source location studies with the LORETA method (low-resolution electromagnetic tomography; Pascual-Marqui et al, 1994) suggest that the two-dimensional NGA phenomenon is based on a strong electrical activity of the medial prefrontal cortex during the NoGo condition (Fallgatter et al, 2002b). Based on these findings, the NGA may be considered as a noninvasive electrophysiological measurement of medial prefrontal brain function involved in response inhibition processes. This association with response inhibition, however, is still under debate and may even be absent in the auditory modality (Salisbury et al, 2004).

In fact, patients with schizophrenias (Fallgatter and Müller, 2001; Fallgatter et al, 2003) are characterized by a diminished NGA indicating an altered function of the medial prefrontal cortex. Concordant alterations of brain function were obtained when investigating patients with obsessive-compulsive disorders (Herrmann et al, 2003) and attention-deficit hyperactivity disorder (ADHD; Fallgatter et al, 2004, Fallgatter et al, 2005a). In addition, patients with schizophreniform and schizophrenic psychoses showed parallel improvements of both NGA and cognitive function as measured by performance in a Stroop test during a 6-week trial with atypical but not with typical neuroleptic compounds (Fallgatter et al, 2005b).

Based on the above-reported genetic and neurophysiological findings, we hypothesized a modulation of NGA as a marker of prefrontal brain function by variation in the $D T N B P 1$ gene. To probe this hypothesis, we investigated the association of eight single-nucleotide polymorphisms (SNPs) in the DTNBP1 gene with NGA in a sample of healthy German individuals.

\section{METHODS}

\section{Subjects}

After complete description of the study, written informed consent was obtained from 54 healthy volunteers. Six participants had to be excluded due to too many artifacts (less than 20 artifact-free EEG epochs in either the Go or the NoGo condition of the electrophysiological investigation). The remaining 48 participants ( 26 female, 22 male) had a mean age of $26.5 \pm 7.2$ years (range 19-63 years). The subjects were healthy, medication -free, and had no lifetime or family history of neurological or psychiatric diseases. In all, 43 of the participants were self-reported right-hander, and five were left-hander. The investigation was approved by the Ethics Committee and by the research conference of the Department of Psychiatry and Psychotherapy of the University of Wüerzburg.

\section{Continuous Performance Test (CPT)}

For the electrophysiological investigation, subjects were seated on a comfortable chair in front of a computer screen in an electrically shielded, dimly lit room to perform the CPT. Letters were presented sequentially in a pseudorandomized order and participants were instructed to press a response button whenever the letter ' $\mathrm{O}$ ' was directly followed by the letter ' $\mathrm{X}$ '. Speed and accuracy were emphasized equally during explanation of the test. The whole stimulus set consisted of 400 letters, with 80 primer conditions $(\mathrm{O}), 40 \mathrm{Go}(\mathrm{O}-\mathrm{X})$ and Nogo (O-any other letter) conditions, and 240 distractors (other letters, or letter X without a preceding $\mathrm{O}$ ). With an interstimulus interval of $1650 \mathrm{~ms}$, each letter was presented for $200 \mathrm{~ms}$. After a short training session, subjects performed this version of the CPT for about 13 min while the EEG was recorded.

\section{EEG Recording and Data Analysis}

The EEG was recorded from 21 electrodes according to the International 10-20 system (Fp1, Fp2, F3, F4, F7, F8, T3, T4, C3, C4, T5, T6, P3, P4, O1, O2, Fpz, Fz, Cz, Pz, and Oz). Three additional electrodes were placed at the outer canthi of both eyes and below the right eye to register horizontal and vertical eye movements. Linked mastoids were used as the recording reference and electrode impedances were constantly kept below $5 \mathrm{k} \Omega$. The recording system consisted of an 80-channel DC amplifier (MI System, Prague, Czech 
Republic). The hardware filter was set to a band pass of $0.1-70 \mathrm{~Hz}$, and A/D rate was $250 \mathrm{~Hz}$.

A computerized artifact rejection excluded all segments with amplitudes exceeding $50 \mu \mathrm{V}$ in any of the EEG or EOG channels within the first $500 \mathrm{~ms}$ after stimulus onset. The remaining artifact-free EEG segments were then averaged to one Go and one NoGo ERP for each participant, whereby only trials with correct responses were included. In the individual Go and NoGo ERPs, the global field power (GFP; Lehmann and Skrandies, 1980) peaks were determined within a P300 microstate $(240-440 \mathrm{~ms})$. Over the electrode position $\mathrm{Fz}$, a positive peak was detected in the time window between $284 \mathrm{~ms}$ until $440 \mathrm{~ms}$. The GFP represents the mean of all possible potential differences in a given scalp potential field and is used as an estimator of the electrical field strength in multichannel recordings. At the individual GFP peaks, the amplitude, latency, and anterior-posterior location of the positive centroid (the amplitude-weighted center of gravity of the positive brain-electrical field; Lehmann, 1987) were calculated.

\section{Two- and Three-Dimensional Analysis of ERP Data}

A two-dimensional delineation of the electrode array was used as a coordinate system with the integers 1-5 indicating the electrode positions in the anterior-posterior direction to quantify the centroid locations. Finally, the NGA, defined as the distance between the individual Go and NoGo centroid within this coordinate system, was calculated separately for each subject. For the analyses of the two-dimensional maps, we compared the amplitudes of each of the three midline electrode positions $\mathrm{Fz}, \mathrm{Cz}$, and $\mathrm{Pz}$ at the individual time points of the GFP peaks between individuals of the different $D T N B P 1$ genotype groups (Figure 1), and displayed a statistical map using the corresponding $t$-values ( $t$-test for independent samples; Figure 2).

For an attempt at three-dimensional delineation of the brain electrical sources of the Go-ERP, we applied the LORETA method (Pascual-Marqui et al, 1994; Figure 3). LORETA calculates the current density at each of the 2394 voxels in the gray matter and the hippocampus of a reference brain (MNI 305; Brain Imaging Centre, Montreal
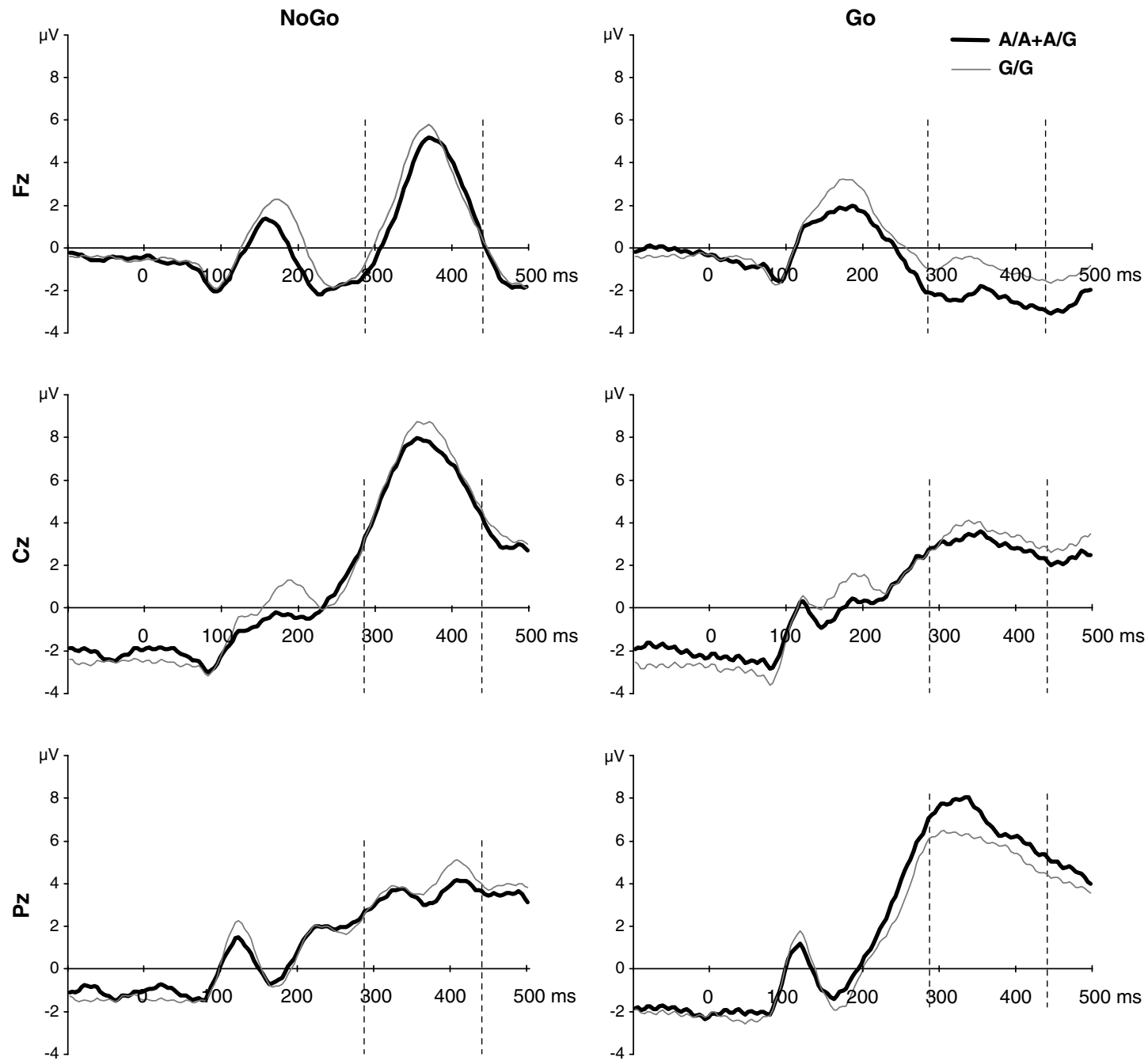

Figure I Traditional ERP waveforms from $100 \mathrm{~ms}$ before to $500 \mathrm{~ms}$ after the NoGo- (left) and the Go-stimulus (right) as derived from midline electrodes ( Fz, Cz, and Pz). ERPs from the PI765 G/G group are displayed in thin lines, and from the PI765 A/A + A/G group in heavy lines. Vertical lines mark the beginning and the end for the analyzed time segment (284-440 ms). 
Neurologic Institute) based on the linear, weighted sum of the scalp electric potentials. LORETA chooses the smoothest of all possible current density configurations throughout the brain volume by minimizing the total squared Laplacian of source strengths. This procedure only implicates that neighboring voxels should have a maximally similar electrical activity, no other assumptions are made. The applied version of LORETA used a three-shell spherical head model registered to the Talairach space. It has been shown that LORETA is able to localize sources for cognitive tasks reliably (eg Herrmann and Fallgatter, 2004). However, interpretations of the neuroanatomical results given by LORETA have to be carried out cautiously since all EEG source localization methods including LORETA can only give approximations but no definitive solutions of the so-called inverse problem (eg Michel et al, 2004). We used

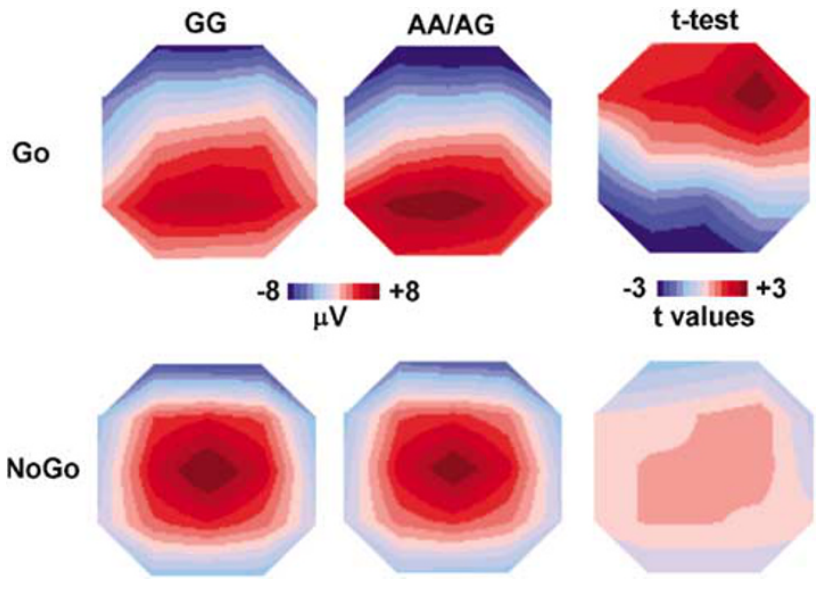

Figure 2 The distribution of the averaged brain electrical activity at the time point of GFP peaks for subjects with the DTNBP I gene polymorphism PI765 genotypes G/G (left) and A/A + A/G (middle) for the Go (above) and the NoGo condition (below). Additionally, on the right side the statistical t-maps comparing the amplitudes of the $G / G$ group with the A/A $+\mathrm{A} / \mathrm{G}$ group are displayed for both conditions.
LORETA to calculate the three-dimensional localization of the electrical sources contributing to the electrical scalp field for each subject and condition at the time point of the individual GFP peaks.

\section{Genotyping}

DNA was extracted from whole-blood samples using standard protocols. Eight SNPs (Table 1) that cover the $D T N B P 1$ gene and its $5^{\prime}$ - and $3^{\prime}$-flanking region were genotyped by TaqMan $5^{\prime}$ exonuclease allelic discrimination assays (Applied Biosystems, Darmstadt, Germany). Preparation of the PCR reaction mixtures was performed by Genesis Workstation RSP 150 (Tecan, Crailsheim, Germany). For PCR amplification and allelic discrimination, the ABI Prism 7900 HT Sequence Detection System and SDS software version 2.1 (Applied Biosystems, Darmstadt, Germany) were used.

\section{Statistical Analysis}

All polymorphisms were in Hardy-Weinberg equilibrium ( $p>0.05$; assessed by online resource www.kursus.kvl.dk/ shares/vetgen/_Popgen/genetik/applets/kitest.htm; for genotype frequencies, see Table 1). As for some polymorphisms (P1635, P1325, P1586), only two genotypes were present, and for most with three genotypes, the number of individuals with one genotype was below $N=5$ ( $\mathrm{P} 1730$, $\mathrm{P} 1765, \mathrm{P} 1320, \mathrm{P} 1140)$, the genotypes $\mathrm{G} / \mathrm{C}$ and $\mathrm{C} / \mathrm{C}$ of P1730, G/C and G/G of P1655, A/G and A/A of P1765, C/T and T/T of P1320 as well as A/C and C/C of P1140 were combined into one group each for the subsequent analysis without $a$ priori hypothesis to allow for comparable power in statistical analyses. Owing to the overall low heterozygosity rate with only two individuals with $\mathrm{T} / \mathrm{C}$ at the P1586 locus, no meaningful statistical analysis of an association with the NGA could be performed for this polymorphism. Linkage disequilibrium (LD) was analyzed by Haploview version 3.2 (http://www.broad.mit.edu/mpg/haploview). The P1765 and P1320 polymorphisms were in complete LD as well as in

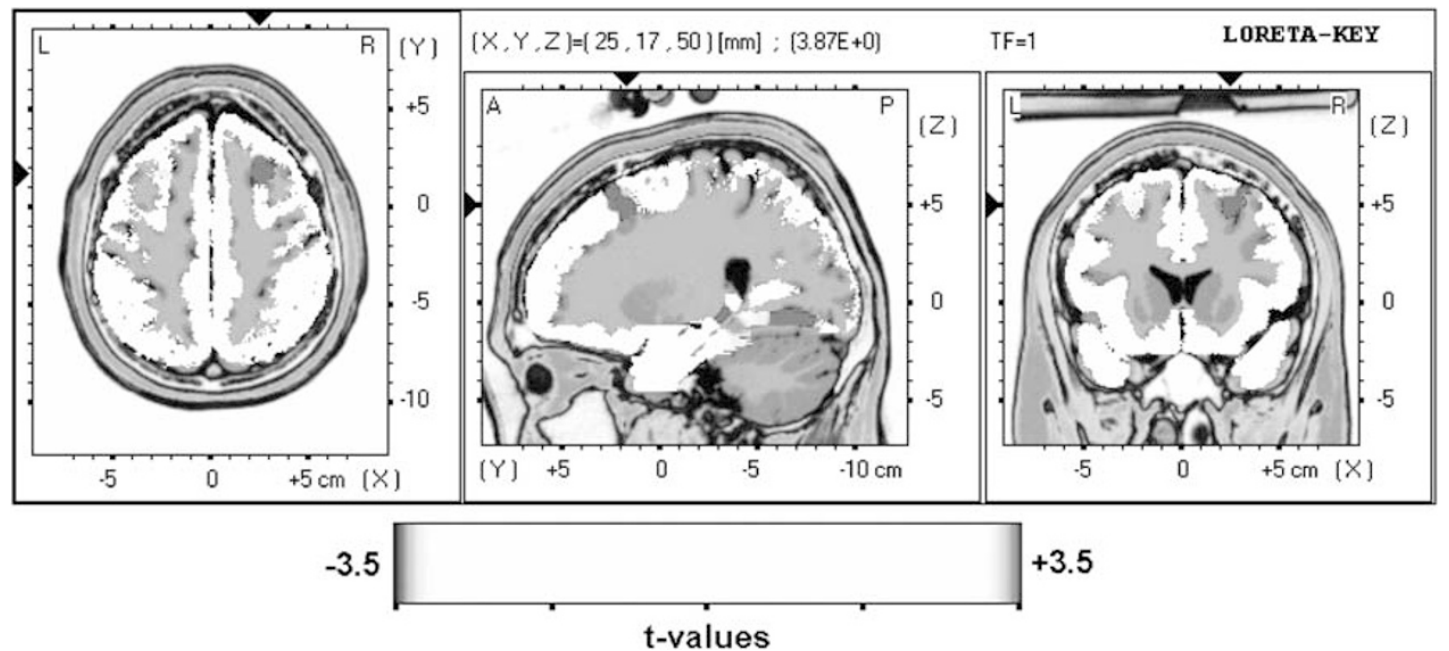

Figure 3 Comparison of LORETA source localization between subjects with the DTNBPI gene polymorphism PI765 genotypes G/G and A/A + A/G for the Go condition. Red (black) color indicates significantly higher brain activity for G/G subjects. 
Table I Polymorphisms of the DTNBPI (Dysbindin) Gene

\begin{tabular}{|c|c|c|c|c|}
\hline SNP ${ }^{a}, d b S N P I^{b}$ & Allele & SNP location & SNP position ${ }^{c}$ & Genotype frequencies \\
\hline PI730, rs | 474588 & $\mathrm{G} / \mathrm{C}$ & $3^{\prime}$-flanking region & 15569688 & $\mathrm{G} / \mathrm{G}=23, \mathrm{G} / \mathrm{C}=22, \mathrm{C} / \mathrm{C}=3$ \\
\hline PI655, rs2619539 & $\mathrm{C} / \mathrm{G}$ & Intron 5 & 15728834 & $C / C=18, G / C=21, G / G=9$ \\
\hline PI635, rs32I3207 & $A / G$ & Intron 4 & $1573608 \mid$ & $\mathrm{A} / \mathrm{A}=37, \mathrm{~A} / \mathrm{G}=1 \mathrm{I}, \mathrm{G} / \mathrm{G}=0$ \\
\hline $\mathrm{PI} 325, \mathrm{rs} 1011313$ & $G / A$ & Intron 4 & $1574|4| \mid$ & $\mathrm{G} / \mathrm{G}=40, \mathrm{~A} / \mathrm{G}=8, \mathrm{~A} / \mathrm{A}=0$ \\
\hline PI765, rs26|9528 & $\mathrm{G} / \mathrm{A}$ & Intron 3 & 15757808 & $\mathrm{G} / \mathrm{G}=30, \mathrm{~A} / \mathrm{G}=17, \mathrm{~A} / \mathrm{A}=1$ \\
\hline PI586, rs885773 & $\mathrm{C} / \mathrm{T}$ & $5^{\prime}$-flanking region & I5 577465 & $C / C=46, T / C=2, T / T=0$ \\
\hline$P|| 40, r s|0001| 7$ & $\mathrm{~A} / \mathrm{C}$ & $5^{\prime}$-flanking region & 15981968 & $\mathrm{~A} / \mathrm{A}=26, \mathrm{~A} / \mathrm{C}=18, \mathrm{C} / \mathrm{C}=4$ \\
\hline
\end{tabular}

astraub et al (2002).

${ }^{b} \mathrm{NCBI}$ number (http://www.ncbi.nlm.nih.gov/SNP).

'UCSC Genome Browser, Human May 2004 Assembly (http://genome.ucsc.edu/cgi-bin/hgGateway).

Table 2 Pairwise LD in DTNBPI Polymorphisms as Measured by $D^{\prime}$ (Top Diagonal) and $r^{2}$ (Bottom Diagonal)

PI730 PI655 PI635 PI325 PI765 PI320 PI586 PII40

\begin{tabular}{lllllllll}
\hline $\mathrm{PI} 730$ & - & 0.15 & $\boldsymbol{I . 0}$ & $\boldsymbol{I . 0}$ & 0.02 & 0.02 & 0.52 & 0.28 \\
$\mathrm{PI} 655$ & 0.01 & - & $\boldsymbol{I . 0}$ & $\boldsymbol{I . 0}$ & 0.05 & 0.05 & $\boldsymbol{I . 0}$ & 0.04 \\
$\mathrm{PI} 635$ & 0.05 & 0.19 & - & 0.03 & $\boldsymbol{I . 0}$ & $\boldsymbol{I . 0}$ & 0.36 & 0.47 \\
$\mathrm{PI} 325$ & 0.04 & 0.13 & 0.0 & - & $\boldsymbol{I . 0}$ & $\boldsymbol{I . 0}$ & $\boldsymbol{I . 0}$ & 0.2 \\
$\mathrm{PI} 765$ & 0.0 & 0.0 & $\mathbf{0 . 5 2}$ & 0.02 & - & $\boldsymbol{I . 0}$ & 0.18 & 0.09 \\
$\mathrm{PI} 320$ & 0.0 & 0.0 & $\mathbf{0 . 5 2}$ & 0.02 & $\boldsymbol{I . 0}$ & - & 0.18 & 0.09 \\
$\mathrm{PI} 586$ & 0.0 & 0.03 & 0.02 & 0.23 & 0.0 & 0.0 & - & $\boldsymbol{I . 0}$ \\
$\mathrm{PII} 40$ & 0.07 & 0.0 & 0.01 & 0.01 & 0.0 & 0.0 & 0.06 & -
\end{tabular}

$D^{\prime}$ values $>0.8$ and $r^{2}$ values $>0.5$ are in boldface italic.

nearly complete LD with the P1635 polymorphism (for all $D^{\prime}=1.0$ and $r^{2}>0.5$; see Table 2). Haplotype blocks were assigned using the solid spine of LD method of Haploview, which resulted in three different blocks containing P1730P1655-P1635 (block 1), P1325-P1765-P1320 (block 2), and P1586-P1140 (block 3). Haplotypes were reconstructed on an individual level by PHASE, version 2.1 (Stephens et al, 2001; Stephens and Donnelly, 2003), based on pairwise standardized LD coefficient $D^{\prime}>0.95$ and a probability of reconstructed pairs of haplotypes for each individual $\geqslant 0.91$. One individual with a probability of $>0.60$ for the haplotype P1586-P1140 was excluded from the respective analysis. By this, three haplotypes of P1325-P1765-P1320 (A-G-C, G-A-T, and G-G-C) and two haplotypes of P1586P1140 (C-C and C-A) could be assessed. Individual haplotypes were coded as two copies (2), one copy (1), or not (0) present in an individual. Because of haplotype frequencies less than $N=5$, for haplotype G-A-T groups (1) and (2) were combined, for haplotype G-G-C groups (0) and (1), for haplotype C-C groups (1) and (2) as well as for haplotype C-A groups (0) and (1).

To reduce the number of statistical tests, we compared in a first step only the NGA between genotypes of seven SNPs and between groups of five haplotypes using $t$-tests for independent samples with a corresponding corrected $p<0.05 / 7=0.0071$ for single-marker analyses and $p<0.05$ / $5=0.01$ for haplotype analyses, respectively. For significant differences between genotypes and haplotypes, post hoc $t$ tests and Wilcoxon's rank-sum tests for independent samples were used to elaborate the electrophysiological parameters that might contribute to these differences.

\section{RESULTS}

The mean reaction time for Go trials in the CPT was $428.6 \pm 87.7 \mathrm{~ms}$. The error rate was very low. On average, participants made $0.6 \pm 0.8$ commission errors (ie button presses after a NoGo trial) and $0.2 \pm 0.4$ omission errors (ie missed button presses after a Go trial).

The NGA as our primary measure of prefrontal brain function had a mean value of $0.75 \pm 0.53$ electrode distances for the whole group of 48 healthy subjects. This result was nearly identical with the mean NGA values reported in three previous normative samples $(0.78 \pm 0.47$, Fallgatter et al, 1997; $0.76 \pm 0.23$, Fallgatter and Strik, 1999; $0.76 \pm 0.33$, Fallgatter et al, 2000). However, in the present study, subjects with genotypes containing the A-allele (A/A and A/ G) of the P1765 polymorphism are characterized by a significantly higher NGA as compared to subjects homozygous for the G-allele $(1.00 \pm 0.44$ vs $0.58 \pm 0.52$; $t=2.84$, $p<0.0068)$. The neighboring and completely linked SNP P1320 also shows the same association, with the NGA being significantly higher in subjects with the T-allele $(\mathrm{C} / \mathrm{T}$ and $\mathrm{T} /$ $\mathrm{T})$ as compared to subjects homozygous for the C-allele. Consistent with this, subjects having one or two copies of the haplotype G-A-T of block 2 are characterized by significantly higher NGA as compared to subjects in whom no copy is present $(1.00 \pm 0.44$ vs $0.58 \pm 0.52 ; t=-2.84$, $p<0.0068$ ). In contrast, the neighboring SNPs in the $3^{\prime}$ and in the $5^{\prime}$ directions as well as the other haplotypes do not show any association with the NGA (Tables 3 and 4).

As the subjects in the P1765 subgroup $\mathrm{A} / \mathrm{A}+\mathrm{A} / \mathrm{G}$ and the P1320 subgroup $\mathrm{C} / \mathrm{T}+\mathrm{T} / \mathrm{T}$ are identical due to the complete LD between both SNPs, only the post hoc tests for the P1765 polymorphism are reported.

The differential NGA between subjects with P1765 A/A + A/G and subjects with P1765 G/G variants seems to be 
Table 3 Comparing DTNBP / Gene Allele Combinations with respect to the Electrophysiological Parameter of Prefrontal Brain Activation NGA

\begin{tabular}{lcccccc}
\hline SNP & Allele & N & NGA mean & SD & t & P \\
\hline PI730 & C/G+C/C & 25 & 0.80 & 0.53 & & \\
& G/G & 23 & 0.68 & 0.53 & 0.76 & 0.45 \\
PI655 & C/C & 18 & 0.77 & 0.57 & & \\
& C/G+G/G & 30 & 0.72 & 0.51 & 0.28 & 0.77 \\
PI635 & A/A & 37 & 0.69 & 0.55 & & \\
& A/G & 11 & 0.90 & 0.41 & -1.13 & 0.27 \\
PI325 & A/G & 8 & 0.65 & 0.41 & & \\
& G/G & 40 & 0.76 & 0.55 & -0.50 & 0.62 \\
PI765 & A/A+A/G & 18 & 1.00 & 0.44 & & \\
& G/G & 30 & 0.58 & 0.52 & 2.84 & 0.0068 \\
PI320 & C/C & 30 & 0.58 & 0.52 & & \\
& C/T+T/T & 18 & 1.00 & 0.44 & -2.84 & 0.0068 \\
PII40 & C/C+C/A & 22 & 0.71 & 0.56 & & \\
& A/A & 26 & 0.77 & 0.51 & -0.39 & 0.70 \\
\hline
\end{tabular}

$\mathrm{SD}=$ standard deviation

caused predominantly by the localization of the Go centroid (Table 5, Figure 2) with a more frontal localization of the Go centroid resulting in a reduced NGA in the subgroup with $\mathrm{G} / \mathrm{G}(t=2.53, p<0.05)$. This result is underscored by significantly higher amplitudes in the $G / G$ than in the $\mathrm{A} / \mathrm{A}+\mathrm{A} / \mathrm{G}$ subgroup as measured at electrode position $\mathrm{Fz}$ in the investigated $\mathrm{P} 300$ time window $(1.34 \pm 2.39$ vs $-0.26 \pm 1.97 \mu \mathrm{V} ; t=2.38, p<0.05$; Table 5, Figure 1). In contrast, no clear differences between groups occur in the respective $\mathrm{P} 300$ time window at the electrode positions $\mathrm{Cz}$ and $\mathrm{Pz}$ (Figure 1). Furthermore, no significant differences between genotypes regarding GFP amplitudes and latencies are observed. Haplotype analysis again confirmed genotype results by demonstrating distinctly more frontal localization of the Go centroid and distinctly higher amplitudes at electrode position $\mathrm{Fz}$ for subjects having no copy of the GA-T haplotype of block $2(Z=2.64, p<0.05$ and $Z=-2.65$, $p<0.05$; Table 6 ), which corresponds to significantly reduced NGA (shown above).

Subjects of the P1765 A/A + A/G subgroup do not differ from the subjects of the $\mathrm{P} 1765 \mathrm{G} / \mathrm{G}$ group with respect to omission errors (A/A + A/G: $m=0.33 \pm 0.7 ; \mathrm{G} / \mathrm{G}: m=0.70 \pm$ $0.9 ; t[46]=-1.5, p=0.15)$, commission errors $(\mathrm{A} / \mathrm{A}+\mathrm{A} / \mathrm{G}$ : $m=0.22 \pm 0.5 ; \mathrm{G} / \mathrm{G}: m=0.13 \pm 0.3 ; t[46]=-0.7, p=0.49$ ), or reaction times $(\mathrm{A} / \mathrm{A}+\mathrm{A} / \mathrm{G}: \mathrm{m}=435.1 \pm 106.0 \mathrm{~ms} ; \mathrm{G} / \mathrm{G}$ : $\mathrm{m}=424.7 \pm 79.0 \mathrm{~ms} ; t[46]=0.7, p=0.70)$.

To illustrate the more frontal activation during the Go condition for the P1765 G/G subjects compared to the P1765 $\mathrm{A} / \mathrm{A}+\mathrm{A} / \mathrm{G}$ subjects, we displayed the distribution of the brain electrical activity by means of a statistical map for differences. The higher right frontal activity for the G/G subjects during the Go condition can be clearly discerned (Figure 2). At a three-dimensional level, the source localization (LORETA) revealed significant $(p<0.05)$ differences between subjects with P1765 G/G compared to subjects with P1765 A/A + A/G in five different regions including the right hemispheric middle frontal gyrus and
Table 4 Haplotype Frequencies and Comparison of Haplotype Groups with respect to the Electrophysiological Parameter of Prefrontal Brain Activation NGA

\begin{tabular}{lrrrrrr}
\hline Haplotype & Copy number & $\boldsymbol{N}$ & NGA mean & SD & $\boldsymbol{t}$ & $\boldsymbol{P}$ \\
\hline Block 2 & 0 & 40 & 0.76 & 0.55 & & \\
A-G-C & 1 & 8 & 0.65 & 0.41 & 0.50 & 0.62 \\
& 0 & 30 & 0.58 & 0.52 & & \\
G-A-T & $1+2$ & $17+1$ & 1.00 & 0.44 & -2.84 & 0.0068 \\
& $0+1$ & $3+21$ & 0.90 & 0.47 & & \\
G-G-C & 2 & 24 & 0.58 & 0.54 & 2.24 & 0.0302 \\
& & & & & & \\
Block 3 & 0 & 26 & 0.77 & 0.51 & & \\
C-C & $1+2$ & $18+3$ & 0.71 & 0.58 & 0.38 & 0.70 \\
& $0+1$ & $3+18$ & 0.71 & 0.58 & & \\
C-A & 2 & 26 & 0.77 & 0.51 & -0.38 & 0.70 \\
\hline SD = standard deviation. & & & & & &
\end{tabular}

Table 5 Post Hoc Test for the Electrophysiological Parameters between Allelic Variations of the DTNBP I Gene Polymorphism PI765

\begin{tabular}{|c|c|c|c|c|c|c|c|}
\hline Parameter & Condition & Allele & $\mathbf{N}$ & Mean & SD & $t / Z^{\mathrm{a}}$ & $p$ \\
\hline \multirow[t]{2}{*}{ NGA } & & $\mathrm{A} / \mathrm{A}+\mathrm{A} / \mathrm{G}$ & 18 & 1.00 & 0.44 & 2.84 & 0.0068 \\
\hline & & $\mathrm{G} / \mathrm{G}$ & 30 & 0.58 & 0.52 & & \\
\hline \multirow[t]{4}{*}{ Centroid } & Go & $\mathrm{A} / \mathrm{A}+\mathrm{A} / \mathrm{G}$ & 18 & 4.00 & 0.28 & $2.64^{\mathrm{a}}$ & $0.008^{a}$ \\
\hline & & $\mathrm{G} / \mathrm{G}$ & 30 & 3.69 & 0.47 & & \\
\hline & NoGo & $\mathrm{A} / \mathrm{A}+\mathrm{A} / \mathrm{G}$ & 18 & 3.00 & 0.40 & $-0.50^{a}$ & $0.62^{\mathrm{a}}$ \\
\hline & & G/G & 30 & 3.11 & 0.51 & & \\
\hline \multirow[t]{4}{*}{ GFP $(\mu \vee)$} & Go & $\mathrm{A} / \mathrm{A}+\mathrm{A} / \mathrm{G}$ & 18 & 5.80 & 1.71 & 1.38 & 0.18 \\
\hline & & $\mathrm{G} / \mathrm{G}$ & 30 & 5.11 & 1.67 & & \\
\hline & NoGo & $\mathrm{A} / \mathrm{A}+\mathrm{A} / \mathrm{G}$ & 18 & 4.72 & 1.00 & -1.52 & 0.14 \\
\hline & & $\mathrm{G} / \mathrm{G}$ & 30 & 5.33 & 1.49 & & \\
\hline \multirow[t]{4}{*}{ Latency (ms) } & Go & $\mathrm{A} / \mathrm{A}+\mathrm{A} / \mathrm{G}$ & 18 & 343.6 & 40.3 & 1.41 & 0.17 \\
\hline & & $\mathrm{G} / \mathrm{G}$ & 30 & 327.1 & 38.7 & & \\
\hline & NoGo & $\mathrm{A} / \mathrm{A}+\mathrm{A} / \mathrm{G}$ & 18 & 368.2 & 32.6 & 0.59 & 0.56 \\
\hline & & $\mathrm{G} / \mathrm{G}$ & 30 & 362.3 & 35.0 & & \\
\hline \multirow{4}{*}{$\begin{array}{l}\text { Fz amplitudes } \\
(\mu \mathrm{V})\end{array}$} & Go & $\mathrm{A} / \mathrm{A}+\mathrm{A} / \mathrm{G}$ & 18 & -0.26 & 1.97 & $-2.65^{a}$ & $0.008^{a}$ \\
\hline & & $\mathrm{G} / \mathrm{G}$ & 30 & 1.34 & 2.39 & & \\
\hline & NoGo & $\mathrm{A} / \mathrm{A}+\mathrm{A} / \mathrm{G}$ & 18 & 5.93 & 1.56 & $0.33^{\mathrm{a}}$ & $0.74^{\mathrm{a}}$ \\
\hline & & $\mathrm{G} / \mathrm{G}$ & 30 & 6.50 & 3.37 & & \\
\hline
\end{tabular}

Wilcoxon's rank-sum test.

$\mathrm{SD}=$ standard deviation

the hippocampus (hippocampus, Talairach space in $\mathrm{mm}$ : $X=32, Y=-39, Z=-6, \quad t$-value $=3.96$; lingual gyrus, Brodman area $(\mathrm{BA})=19 ; \quad X=18, \quad Y=-67, \quad Z=-6$, $t=3.93$; middle frontal gyrus, $\mathrm{BA}=8, X=25, \quad Y=17$, $Z=50, t=3.87$; fusiform gyrus, $\mathrm{BA}=37, X=39, Y=-60$, $Z=-20, \quad t=3.62 ;$ postcentral gyrus, $\mathrm{BA}=3, \quad X=66$, $Y=-11, Z=29, t=-3.52$; Figure 3). 
Table 6 Post Hoc Test for the Electrophysiological Parameters Centroid and Fz Amplitudes ( $\mu \mathrm{V}$ ) with the Condition Go between the G-A-T Haplotype Groups of Block 2 (PI325-PI765-PI320)

\begin{tabular}{lcrrrrrr}
\hline Parameter & Haplotype Copy number & $\boldsymbol{N}$ & Mean & SD & $\boldsymbol{Z}$ & $\boldsymbol{P}$ \\
\hline Centroid & G-A-T & 0 & 30 & 3.69 & 0.47 & & \\
& & $1+2$ & $17+1$ & 4.00 & 0.28 & 2.64 & 0.008 \\
Fz amplitudes & G-A-T & 0 & 30 & 1.34 & 2.39 & & \\
& & $1+2$ & $17+1$ & -0.26 & 1.97 & -2.65 & 0.008
\end{tabular}

$\mathrm{SD}=$ standard deviation

\section{DISCUSSION}

To our best knowledge, this study is the first to show an association of a variant of the DTNBP1 gene with a neurophysiological parameter of prefrontal brain function in healthy subjects.

DTNBP1 (dysbindin) is considered as one of the bestvalidated candidate genes for schizophrenic diseases (Harrison and Weinberger, 2005). The molecular mechanisms by which DTNBP1 acts in the brain and their functional consequences in subjects with variants in the DTNBP1 gene, however, are far from being understood. One way to further investigate these functional consequences is to correlate $D T N B P 1$ gene variants with measurements of functional intermediate phenotypes (endophenotypes), which are well characterized in healthy subjects and disturbed in schizophrenic patients. These two prerequisites are particularly true for the NGA, a robust and reliable ERP marker of prefrontal brain function that has been described disturbed with markedly reduced NGA in patients with schizophrenias (Fallgatter and Müller, 2001; Fallgatter et al, 2003). In this context, the significantly reduced NGA in healthy subjects with the G/G variant of SNP P1765 as well as the $\mathrm{C} / \mathrm{C}$ variant of SNP P1320 may be cautiously interpreted as an expression of mildly disturbed prefrontal brain function. The P1765 and P1320 polymorphisms as well as the haplotype block P1325-P1765-P1320 associated with disturbed prefrontal brain function in these healthy German individuals are identical to those associated with schizophrenia in a German schizophrenia sample (Schwab et al, 2003). Our observations of a DTNBP1 genotype effect on prefrontal brain function are not only consistent with a series of linkage studies in schizophrenia (for a review see Funke et al, 2004) but also with findings describing an association of DTNBP1 gene polymorphisms with other cognitive intermediate phenotypes such as IQ, working, and episodic memory (Straub et al, 2003).

A closer look at the electrophysiological results reveals that the differential NGA in this study in contrast to previous findings in patients with schizophrenia is mainly caused by a change of the centroid location in the Go condition and not in the NoGo condition. This suggests that in the healthy P1765 G/G or P1320 C/C subjects, on a neurophysiological level, the execution of a motor response is the affected process and not the inhibition (NoGo condition). The significantly higher amplitudes as measured at electrode position Fz (Table 5; Figure 1) as well as the two-dimensional (brain maps; Figure 2) and three-dimensional (LORETA; Figure 3) indications for a stronger activation of right hemispheric prefrontal brain areas in the P1765 G/G group further support the notion that the described alterations in execution-related processes are at least in part due to differences in frontal brain function. However, it has to be mentioned that the source analyses with LORETA found not only the right hemispheric middle frontal gyrus but also four more regions to be significantly different between DTNBP1 P1765 genotypes. Prominent among them is the hippocampus, where DTNBP1 expression levels have been shown to be reduced in patients with schizophrenia similarly to prefrontal cortex (Talbot et al, 2004; Weickert et al, 2004). As DTNBP1 expression levels are inversely correlated with VgluT-1 expression (Talbot et al, 2004), it is conceivable that cognitive processes involving the hippocampus and prefrontal cortex are affected by $D T N B P 1$ gene variation.

It might be argued that differences in brain function should also be reflected in behavioral measures. This is not the case in our study where both genotype samples did not differ in terms of error rates or reaction times. This missing behavioral effect might be explained by the easiness of the applied task with very long interstimulus intervals (1650 $\mathrm{ms})$ and presentation times $(200 \mathrm{~ms})$. This particularly undemanding task has been designed to produce clearcut electrophysiological results, but is rather unsuited for the detection of performance differences between different patient samples and control subjects (eg schizophrenias: Fallgatter and Müller, 2001; Fallgatter et al, 2003; writer's cramp: Berg et al, 2001; ADHD: Fallgatter et al, 2005a; OCD: Herrmann et al, 2003). It is therefore plausible to expect differences in the brain function without accompanying behavioral effects when comparing two healthy samples with this particular task.

Another point of criticism may be that the sample size with 48 individuals is small compared to sample sizes employed in classical association studies based on categorical phenotypes such as schizophrenia. However, it has to be noted that the sample size is quite comparable to those replicating linkage findings in schizophrenia by utilizing dimensional intermediate phenotypes of the hippocampal and prefrontal cortex function (Egan et al, 2004). Nevertheless, replication in independent and preferably larger samples, possibly also with other functional paradigms of prefrontal brain function, is warranted.

In summary, this is the first report of a modulation of prefrontal brain function at the neurophysiological level by DTNBP1 gene variants. Obviously, the reported differences in healthy subjects with different variants of the DTNBP1 gene as measured by ERPs during the execution of a motor response needs replication in a sample of patients with schizophrenia. Such ERP measures elicited during GoNoGo paradigms may reflect one mechanism by which DTNBP1 gene variants contribute to the pathophysiology underlying schizophrenic diseases.

\section{ACKNOWLEDGEMENTS}

The excellent technical support of Kathrin Schwarte is highly acknowledged. The study was supported by an IMF Grant to Christa Hohoff (HO 210406 ) and by the Deutsche Forschungsgemeinschaft (Grant KFO 125/1-1). 


\section{REFERENCES}

Berg D, Herrmann M, Müller ThJ, Strik WK, Aranda D, Koenig Th et al (2001). Cognitive response control in writer's cramp. Eur J Neurology 8: 587-594.

Canli T, Omura K, Haas BW, Fallgatter A, Constable RT, Lesch KP (2005). Beyond affect: a role for genetic variation of the serotonin transporter in neural activation during a cognitive attention task. Proc Natl Acad Sci USA 102: 12224-12229.

Caspi A, Sugden K, Moffitt TE, Taylor A, Craig IW, Harrington H et al (2003). Influence of life stress on depression: moderation by a polymorphism in the 5-HTT gene. Science 301: 386-390.

Egan MF, Goldberg TE, Kolachana BS, Callicot JH, Mazzanti CM, Straub RE et al (2001). Effect of COMT Val108/158 Met genotype on frontal lobe function and risk for schizophrenia. Proc Natl Acad Sci USA 98: 6917-6922.

Egan MF, Straub RE, Goldberg TE, Yakub I, Callicott JH, Hariri AR et al (2004). Variation in GMR3 affects cognition, prefrontal glumatate and risk for schizophrenia. Proc Natl Acad Sci USA 101: 12604-12609.

Fallgatter AJ, Aranda DR, Bartsch AJ, Herrmann MJ (2002a). Longterm reliability of electrophysiological response control parameters. J Clin Neurophysiol 19: 61-66.

Fallgatter AJ, Bartsch AJ, Herrmann MJ (2002b). Electrophysiological measurements of anterior cingulate function. $J$ Neur Transm 109: 977-988.

Fallgatter AJ, Bartsch AJ, Strik WK, Müller ThJ, Eisenack S, Neuhauser B et al (2001). Reliability of electrophysiological parameters assessing human motor control. Clin Neurophysiol 112: 198-204.

Fallgatter AJ, Bartsch AJ, Zielasek J, Herrmann MJ (2003). Brainelectrical dysfunction of the anterior cingulate in schizophrenic patients. Psychiatry Res: Neuroimaging 124: 37-48.

Fallgatter AJ, Brandeis D, Strik WK (1997). A Robust Assessment of the NoGo-anteriorisation of P300 microstates in a cued continuous performance test. Brain Topogr 9: 295-302.

Fallgatter AJ, Ehlis AC, Herrmann MJ (2005b). Does atypical neuroleptic treatment in disorders from the schizophrenia spectrum improve prefrontal brain function? World J Biol Psychiatry 6(Suppl 1): 301.

Fallgatter AJ, Ehlis AC, Rösler M, Strik WK, Blocher D, Herrmann MJ (2005a). Diminished prefrontal brain function in adults with attention deficit hyperactivity disorder (ADHD) related psychopathology in childhood. Psychiatry Res: Neuroimaging 138: 157-169.

Fallgatter AJ, Ehlis AC, Seifert J, Strik WK, Scheuerpflug P, Zillessen $\mathrm{K}$ et al (2004). Altered response control and anterior cingulate function in ADHD boys. Clin Neurophysiol 115: 973-981.

Fallgatter AJ, Eisenack SS, Neuhauser B, Aranda D, Scheuerpflug P, Herrmann MJ (2000). Stability of late event-related potentials: topographical descriptors of motor control compared with the P300 amplitude. Brain Topogr 12: 255-261.

Fallgatter AJ, Jatzke S, Bartsch AJ, Hamelbeck B, Lesch KP (1999a). Serotonin transporter promoter polymorphism influences topography of inhibitory motor control. Int J Neuropsychopharmacol 2: 115-120.

Fallgatter AJ, Müller ThJ (2001). Affection of prefrontal motor control in schizophrenia: an electrophysiological study. Psychiatry Res: Neuroimaging 107: 19-28.

Fallgatter AJ, Müller ThJ, Strik WK (1999b). Age-related changes in brain electrical correlates of response control. Clin Neurophysiol 110: 833-838.

Fallgatter AJ, Strik WK (1999). The NoGo-anteriorisation as a neurophysiological standard-index for cognitive response control. Int J Psychophysiol 32: 233-238.

Funke B, Finn CT, Plocik AM, Lake S, DeRosse P, Kane JM et al (2004). Association of the DTNBP1 locus with schizophrenia in a US population. Am J Hum Genet 75: 891-898.
Hariri AR, Weinberger DR (2003). Imaging genomics. Br Med Bull 65: 259-270.

Harrison PJ, Weinberger DR (2005). Schizophrenia genes, gene expression, and neuropathology: on the matter of their convergence. Mol Psychiatry 10: 40-68.

Herrmann MJ, Fallgatter AJ (2004). Visual oddball paradigm: stability of topographical descriptors and source localization (LORETA) of the P300 component. J Psychophysiol 18: 1-12.

Herrmann MJ, Jacob C, Unterecker S, Fallgatter AJ (2003). Reduced response-inhibition in obsessive-compulsive disorder measured with topographic evoked potential mapping. Psychiatry Res 120: 265-271.

Kirov G, Ivanov D, Williams NM, Preece A, Nikolov I, Milev R et al (2004). Strong evidence for association between the dystrobrevin binding protein 1 gene (DTNBP1) and schizophrenia in 488 parent-offspring trios from Bulgaria. Biol Psychiatry 55: 971-975.

Lehmann D (1987). Principles of spatial analysis. In: Gevins A, Remond A (eds). Handbook of Electroencephalography and Clinical Neurophysiology, Vol. 1. Elsevier: Amsterdam. pp 309-354.

Lehmann D, Skrandies W (1980). Reference-free identification of components of checkerboard-evoked multichannel potential fields. Electroencephalogr Clin Neurophysiol 48: 609-621.

Lesch KP, Bengel D, Heils A, Sabol SZ, Greenberg BD, Petri S et al (1996). Association of anxiety-related traits with a polymorphism in the serotonin transporter gene regulatory region. Science 274: $1483-1487$.

Li W, Zhang Q, Oiso N, Novak EK, Gautam R, O'Brien EP et al (2003). Hermansky-Pudlak syndrome type 7 (HPS-7) results from mutant dysbindin, a member of the biogenesis of lysosome-related organelles complex (BLOC-1). Nat Genet 35: 84-89.

Michel CM, Murray MM, Lantz G, Gonzalez S, Spinelli L, Grave de Peralta R (2004). EEG source imaging. Clin Neurophysiol 115: 2195-2222.

Numakawa T, Yagasaki Y, Ishimoto T, Okada T, Suzuki T, Iwata N et al (2004). Evidence of novel neuronal functions of dysbindin, a susceptibility gene for schizophrenia. Hum Mol Genet 13: 2699-2708.

Pascual-Marqui RD, Michel CM, Lehmann D (1994). Low resolution electromagnetic tomography: a new method for localizing electrical activity in the brain. Int J Psychophysiol 18: 49-65.

Salisbury DF, Griggs CB, Shenton ME, McCarley RW (2004). The NoGo P300 'anteriorization' effect and response inhibition. Clin Neurophysiol 115: 1550-1558.

Schwab SG, Knapp M, Mondabon S, Hallmayer J, BormannHassenbach M, Albus M et al (2003). Support for association of schizophrenia with genetic variation in the $6 \mathrm{p} 22.3$ gene, dysbindin, in sib-pair families with linkage and in an additional sample of triad families. Am J Hum Genet 72: 185-190.

Stephens JC, Schneider JA, Tanguay DA, Choi J, Acharya T, Stanley $\mathrm{SE}$ et al (2001). Haplotype variation and linkage disequilibrium in 313 human genes. Science 293: 489-493.

Stephens M, Donnelly PA (2003). Comparison of Bayesian methods for haplotype reconstruction from population genotype data. Am J Hum Genet 73: 1162-1169.

Straub RE, Egan MF, Hashimoto R, Matsumoto M, Weickert CS, Goldberg TE et al (2003). The schizophrenia susceptibility gene dysbindin (DTNBP1, 6p22.3): analysis of haplotypes, intermediate phenotypes and alternative transcripts. Biol Psychiatry 53: $167 S-168$ S.

Straub RE, Jiang Y, MacLean CJ, Ma Y, Webb BT, Myakishev MV et al (2002). Genetic variation in the 6p22.3 DTNBP1, the human ortholog of the mouse dysbindin gene, is associated with schizophrenia. Am J Hum Genet 71: 337-348.

Talbot K, Eidem WL, Tinsley CL, Benson MA, Thompson EW, Smith RJ et al (2004). Dysbindin-1 is reduced in intrinsic, 
glutamatergic terminals of the hippocampal formation in schizophrenia. J Clin Invest 113: 1353-1363.

van Beijsterveldt CE, van Baal GC (2002). Twin and family studies of the human electroencephalogram: a review and a metaanalysis. Biol Psychol 61: 111-138.

Van den Oord EJCG, Sullivan PF, Jiang Y, Walsh D, O'Neill FA, Kendler KS et al (2003). Identification of a high-risk haplotype for the dystrobrevin binding protein 1 (DTNBP1) gene in the Irish study of high-density schizophrenia families. Mol Psychiatry 8: 499.

VanDenBogaert A, Schumacher J, Schulze TG, Otte AC, Ohlraun S, Lovalenl S et al (2003). The DTNBP1 (dysbindin) gene contributes to schizophrenia, depending on family history of the disease. Am J Hum Genet 73: 1438-1443.
Weickert CS, Straub RE, McClintock BW, Matsumoto M, Hashimoto R, Hyde TM et al (2004). Human dysbindin (DTNBP1) gene expression in normal brain and in schizophrenia prefrontal cortex and midbrain. Arch Gen Psychiatry 61: 544-555.

Williams NM, Preece A, Morris DW, Spurlock G, Bray NJ, Stephens $\mathrm{M}$ et al (2004). Identification in 2 independent samples of a novel schizophrenia risk haplotype of the dystrobrevin binding protein gene (DTNBP1). Arch Gen Psychiatry 61: 336-344.

Winterer G, Egan MF, Raedler T, Sanchez C, Jones DW, Coppola R et al (2003). P300 and genetic risk for schizophrenia. Arch Gen Psychiatry 60: 1158-1167.

Winterer G, Goldman D (2003). Genetics of human prefrontal function. Brain Res Brain Res Rev 43: 134-163. 